\title{
Lidar and in situ observations of continental and Saharan aerosol: closure analysis of particles optical and physical properties
}

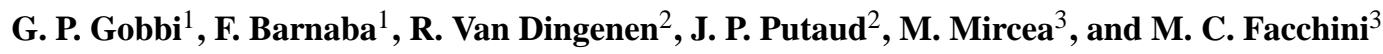 \\ ${ }^{1}$ Istituto di Scienze dell'Atmosfera e del Clima-CNR, Roma, Italy \\ ${ }^{2}$ European Commission Joint Research Centre, Ispra, Italy \\ ${ }^{3}$ Istituto di Scienze dell'Atmosfera e del Clima-CNR, Bologna, Italy
}

Received: 29 October 2002 - Published in Atmos. Chem. Phys. Discuss.: 3 February 2003

Revised: 2 September 2003 - Accepted: 1 October 2003 - Published: 5 December 2003

\begin{abstract}
Single wavelength polarization lidar observations collected at Mt. Cimone $\left(44.2^{\circ} \mathrm{N}, 10.7^{\circ} \mathrm{E}, 1870 \mathrm{~m}\right.$ a.s.l.) during the June 2000 MINATROC campaign are analyzed to derive tropospheric profiles of aerosol extinction, depolarization, surface area and volume. Lidar retrievals for the 2170-2245 m level are compared to the same variables as computed from in situ measurements of particles size distributions, performed at the mountain top Station (2165 m a.s.l.) by a differential mobility analyzer (DMA) and an optical particle counter (OPC). A sensitivity analysis of this closure experiment shows that mean relative differences between the backscatter coefficients obtained by the two techniques undergo a sharp decrease when hygroscopic growth to ambient humidity is considered for the DMA dataset, otherwise representative of dry aerosols. Minimization of differences between lidar and size distribution-derived backscatter coefficients allowed to find values of the "best" refractive index, specific to each measurement. These results show the refractive index to increase for air masses proceeding from Africa and Western Europe. Lidar depolarization was observed to minimize mainly in airmasses proceeding from Western Europe, thus indicating a spherical, i.e. liquid nature for such aerosols. Conversely, African, Mediterranean and East Europe aerosol showed a larger depolarizing fraction, mainly due to coexisting refractory and soluble fractions. The analysis shows average relative differences between lidar and insitu observations of $5 \%$ for backscatter, $36 \%$ for extinction $41 \%$ for surface area and $37 \%$ for volume. These values are well within the expected combined uncertainties of the lidar and in situ retrievals. Average differences further decrease during the Saharan dust transport event, when a lidar signal inversion model considering non-spherical scatterers is employed. The quality of the closure obtained between particle counter and lidar-derived aerosol surface area and volume observations constitutes a validation of the technique
\end{abstract}

Correspondence to: G. P. Gobbi

(g.gobbi@isac.cnr.it) adopted to retrieve such aerosol properties on the basis of single-wavelength lidar observations.

\section{Introduction}

Atmospheric aerosols play a crucial role in determining the Earth radiation balance via two different mechanisms: 1) scattering and absorbing both solar and thermal radiation, 2) acting as cloud condensation nuclei. The radiative forcing anthropogenic aerosols enact via these two mechanisms (in particular the second one) is currently evaluated to be opposite in sign but of the same order and in some regions even larger than the forcing due to current greenhouse gases (e.g. Ramanathan et al., 2001). Also through mechanism (2), in particular by increasing the number of suspended cloud droplets, anthropogenic contribution to aerosol concentrations can inhibit precipitation, therefore modifying the hydrological cycle (Rosenfeld et al., 1999). Furthermore, aerosols provide airborne reactive surfaces for the heterogeneous chemistry processes leading to changes in atmospheric composition (e.g. Jacob, 2000; Balkanski et al., 2003). Understanding of these processes is still considered to be very low (e.g. Penner et al., 2001, and references therein). An improved global picture of atmospheric aerosols and related processes is therefore needed to better address some of the fundamental mechanisms controlling the Earth's climate.

In situ observations play a key role in building the picture of airborne particulate matter. This is because the microphysical and chemical properties of aerosol particles necessary to invert remote sensing (satellite, lidar, sunphotometer) observations are mainly determined by means of these techniques (e.g. Raes et al., 2000). While current satellite passive radiometry experiments start providing global (land and ocean) column contents (e.g. Kaufman et al., 2002), lidars (laser radars) remain best suited at retrieving vertical profiles of atmospheric aerosols (e.g. Franke et al., 2001; Sassen, 2002). In fact, in the near future elastic backscatter lidars will be 
flown onboard space platforms by both NASA (Calipso) and ESA (Earthcare). A quantitative retrieval of aerosol properties by these lidars will require the use of specific algorithms and assumptions. These might lead to rather large errors if erroneously applied (e.g. Karyampudi et al., 1999; Gobbi et al., 2002). Relevant results need then to be validated against in situ or complementary observations.

In this paper we shall compare and discuss lidar and in situ particle size distribution measurements simultaneously collected during an experimental campaign characterized by both continental and Saharan aerosol conditions. The instrumental set up and measurement schemes will be described in Sect. 2. In Sect. 3 we shall present and discuss the evolution of the vertical profiles of aerosol extinction, depolarization, surface area and volume retrieved by the single-wavelength, polarization lidar system. Finally, in Sect. 4 we shall compare lidar retrievals of aerosol backscatter, extinction, surface area and volume for the $2200 \mathrm{~m}$ level to equivalent retrievals computed from in situ particle counters observations carriedout at that altitude. The latter analysis will provide both the best refractive index of the observed aerosols and a closure experiment between lidar and particle counter-derived surface area and volume observations.

\section{Methods}

The European Union (EU) Mineral dust and Tropospheric Chemistry (MINATROC) campaign took place at the Mt. Cimone Station $\left(44.2^{\circ} \mathrm{N}, 10.7^{\circ} \mathrm{E}, 2165 \mathrm{~m}\right.$ a.s.l.) between 1 June and 5 July 2000 (Balkanski et al., 2003). In addition to atmospheric chemistry measurements, aerosol observations were carried out by means of particle sizing instrumentation, by impactors, by optical nephelometer and aethalometer and by the Vehicle-mounted Lidar System (VELIS). For the purposes of our analysis, we shall combine particle size distribution and composition results, together with the VELIS lidar measurements. We start with providing an outline of the observational methods.

\subsection{The VELIS lidar}

VELIS is a compact, mobile polarization lidar designed to provide day and night-time profiles of atmospheric aerosols starting $150 \mathrm{~m}$ from the system and up to the lower stratosphere. VELIS has been developed at the Institute for Sciences of the Atmosphere and Climate (ISAC) of the Italian Research Council (CNR) in Rome (Gobbi et al., 2000). The lidar emitter is based on a frequency doubled $(532 \mathrm{~nm})$ $\mathrm{Nd}$ :YAG laser, generating plane-polarized, $100 \mathrm{~mJ}$ pulses at $15 \mathrm{~Hz}$. A two-receiver configuration is employed to cope with the high dynamic range of the returning signal: a $10 \mathrm{~cm}$ telescope for the near range (150-2000 $\mathrm{m}$ from the system) and a $25 \mathrm{~cm}$ one for the far range $(1.5-20 \mathrm{~km})$. Below $150 \mathrm{~m}$ the signal is corrected to account for the incomplete geo- metrical superposition between the laser beam and the telescope field of view characterizing these levels. The atmospheric backscatter signal is detected by photomultipliers and digitized by photon counting devices. Relative to the polarized laser emission, each receiver detects both parallel, $S_{/ /}$, and perpendicular, $S_{\perp}$, polarization signals. Here $S$ represents the backscatter signal generated by atmospheric molecules $S_{m}$ and aerosols $S_{a}\left(S=S_{m}+S_{a}\right)$, after subtraction of the background noise. Since non-spherical particles introduce some degree of depolarization in the light they backscatter while spherical particles do not, the linear depolarization ratio $D=S_{\perp} / S_{/ /}=\left(S_{m \perp}+S_{a \perp}\right) /\left(S_{m / /}+S_{a / /}\right)$ allows to discriminate liquid (spherical) from solid (nonspherical) particles (e.g. Gobbi, 1998). Aerosol-induced depolarization $D_{a}=S_{a \perp} / S_{a / /}$ (that is the ratio between the aerosol-generated orthogonal signals) represents a useful tool in studying the solid versus liquid aerosol phases (e.g. Gobbi et al., 2000). However, $D_{a}$ can diverge for small aerosol contents and the more straightforward parameter $D$ is often used to give a general picture of atmospheric depolarization. From the just given definitions it is evident that $D$ and $D_{a}$ tend to the same value for $S_{a} \gg S_{m}$. The lidar signal of a specific altitude $z$, is generated by the backscatter of atmospheric molecules and aerosols present at that level and extinguished (by the same constituents) on its way back to the receiver. Assuming that molecular density profiles are known (via either radio-sounding or model data), the lidar equation, relating the signal to its atmospheric causes, then contains the two unknowns $\beta_{a}$ and $\sigma_{a}$, i.e. the aerosol backscatter and extinction coefficients, respectively (e.g. Measures, 1984). A relationship between aerosol extinction and backscatter is then needed to solve this equation (e.g. Klett, 1985). Our analysis of the VELIS observations at Mt. Cimone is performed by employing model-derived functional relationships $\sigma_{a}=f\left(\beta_{a}\right)$ specific to the aerosol types being observed (e.g. Barnaba and Gobbi, 2001). The lidar equation is therefore solved by means of an iteration-convergence procedure: 1) The lidar trace is calibrated against a model atmosphere (obtained from a ten-year climatology of radio-soundings launched $150 \mathrm{~km}$ $\mathrm{N}-\mathrm{W}$ of the site) at an aerosol-free level individuated by visual analysis of the signal. From the model atmosphere the molecular backscatter profile $\beta_{m}(z)$ is obtained. The calibrated lidar signal therefore represents the unattenuated total backscatter profile $\left.\beta_{\mathrm{tot}}(z)=\beta_{m}(z)+\beta_{a}(z) ; 2\right)$ the aerosol backscatter $\beta_{a}\left(z_{i}\right)$ at each measurement point is determined as $\left.\beta_{a}\left(z_{i}\right)=\beta_{\mathrm{tot}}\left(z_{i}\right)-\beta_{m}\left(z_{i}\right) ; 3\right)$ the aerosol extinction $\sigma_{a}$ at each measurement point is obtained from the $\sigma_{a}=f\left(\beta_{a}\right)$ model relationship (either continental or Saharan dust models will be employed here, see discussion below) on the basis of the aerosol backscatter $\beta_{a}$ computed at step $2 ; 4$ ) at each measurement point the calibrated signal $\beta_{\text {tot }}\left(z_{i}\right)$ is corrected for both the aerosol and molecular extinction encountered below that point, then providing a new extinction corrected profile $\left.\beta_{\text {tot }}^{\prime}(z) ; 5\right)$ steps $1-4$ are iterated until convergence 
on integrated aerosol backscatter is reached, according to the condition: $\Sigma_{i}\left|\beta_{a}^{\prime}\left(z_{i}\right)-\beta_{a}\left(z_{i}\right)\right| / \Sigma_{i} \beta_{a}^{\prime}\left(z_{i}\right) \leq 10^{-3}$. Errors in the retrieval of $\beta_{a}\left(z_{i}\right)$ depend on measurement conditions and range. In the case of the VELIS observations at Mt. Cimone, typical errors $d \beta / \beta \approx 20 \%$ have been computed employing the error analysis method of Russell et al. (1979).

To analyze VELIS data collected during the campaign, $\sigma_{a}=f\left(\beta_{a}\right)$ relationships for continental aerosols (Barnaba and Gobbi, 2003) and for Saharan dust (Barnaba and Gobbi, 2001) have been employed. This is justified by the dominating aerosol types being identified on the basis of backtrajectories as mainly continental in the period 1 June-2 July and as Saharan dust in the period 3-5 July (e.g. Sect. 4.3). Once backscatter profiles are retrieved, the backscatter ratio $R=\left(\beta_{a}+\beta_{m}\right) / \beta_{m}$ can be computed. This parameter is very useful at determining the relative contributions of molecules and aerosols to the total atmospheric backscatter.

Aerosol surface area, $S_{a}$, and volume, $V_{a}$, profiles are estimated by relationships $\left(S_{a}=f\left(\beta_{a}\right)\right.$ and $\left.V_{a}=f\left(\beta_{a}\right)\right)$ relating these parameters to backscatter coefficients and obtained by the same aerosol models. In the case of Saharan dust, the functional relationships $\sigma_{a}=f\left(\beta_{a}\right)$ and $S_{a}=f\left(\beta_{a}\right)$ computed for non-spherical particles representative of mineral dust will be employed. Benefits of the spherical versus nonspherical model are discussed in Gobbi et al. (2002). Since the volume-backscatter relationship $V_{a}=f\left(\beta_{a}\right)$ is not available for non-spherical dust particles (Barnaba and Gobbi, 2001), volume estimates will be performed on the basis of the spherical (Mie) model for both continental and Saharan aerosols. In Sect. 4 we shall discuss in depth the relevant results and the effects of non-sphericity on retrieved aerosol optical and physical properties. In the case of continental aerosols, typical (average) uncertainty of the model-based estimates are $25 \%$ for extinction, $30 \%$ for Surface area, and $40 \%$ for Volume (Barnaba and Gobbi 2003). In the case of Saharan dust, expected uncertainties are of $40 \%$ for $\sigma_{a}$, $45 \%$ for $S_{a}$, and $80 \%$ for $V_{a}$, (Barnaba and Gobbi, 2001). It is worth mentioning that the "direct", statistical approach (Barnaba and Gobbi 2001 and Barnaba and Gobbi, 2003) employed in this analysis to retrieve aerosol properties as $\sigma_{a}$, $S_{a}$, and $V_{a}$ from single-wavelength lidar data is substantially different from the "inverse" ones exploiting more complex, multi-wavelength lidar observations to retrieve a wider range of aerosol properties (e.g. Qing et al., 1989; Muller et al., 1999; Veselovskii et al., 2002). Advantages and limits of the two methods can be found in more detail in the relevant references.

During the campaign, VELIS was located at Pian Cavallaro ( $1870 \mathrm{~m}$ a.s.1.), about $300 \mathrm{~m}$ below and $300 \mathrm{~m}$ apart from the Mt. Cimone Station (2165 m a.s.l.) where the aerosol in situ observations were performed. VELIS collected aerosol profiles in the period 2 June-4 July 2000. Both day and night-time observations employed in this paper are the result of five-minute averages, at $75 \mathrm{~m}$ vertical resolution.

\subsection{The particle sizing instrumentation}

Instrumentation for the in-situ particle size distribution measurements was deployed by the European Commission Joint Research Center (JRC) of Ispra. Aerosol number size distributions in the 6-600 $\mathrm{nm}$ dry diameter range were measured by a custom-built Vienna type DMA (length $28 \mathrm{~cm}$ ), using a TSI CPC model 3010 as particle counter. It is important to note that these size distributions were obtained in dry sheath air conditions, hence particles are reduced to their dry size when measured. Number size distributions in the size range $0.3-10 \mu \mathrm{m}$ were measured with an optical particle counter (OPC, GRIMM model 1.108). The optical arrangement inside the instrument is such that the scattered light is detected at an angle of $90 \pm 30^{\circ}$.

Unlike the DMA sampling, the aerosol entering the OPC was not dried. The OPC sizing is based on a calibration with latex spheres, performed by the manufacturer. Sizing of nonspherical dust particles implies uncertainties which are difficult to quantify. Mishchenko et al. (1997) calculated ratios for non-spherical (prolate and oblate spheroids, representative of dust properties) to spherical phase functions for scattering angles from $60^{\circ}$ to $120^{\circ}$ to be in the range 0.8 to 1.8 , at $90^{\circ}$ the ratio being near 1.2. Therefore, some overestimation might affect the size retrieval in the presence of nonspherical particles. Overall, the expected uncertainties in the particle counters-derived aerosol concentrations, surface area and volume are of 16\%, 22\% and 29\%, respectively (Putaud et al., 2000).

\section{Lidar profiles during MINATROC}

An overview of the lidar retrievals collected during the Mt. Cimone campaign is given in Fig. 1. Here are reported the contour plots of the $532 \mathrm{~nm}$ extinction coefficient $\sigma_{a}$ (Fig. 1a), depolarization ratio $D$ (Fig. 1b), surface area (Fig. 1c) and volume (Fig. 1d), respectively. Uncertainty of these retrievals has been given in Sect. 2.1. These plots allow to see both the maximum height reached by aerosols and the presence of a daily cycle. In general, both features were determined by the daily inflation of the planetary boundary layer (PBL) and aerosols are observed to reach maximum heights of approximately $3 \mathrm{~km}$ in the second half of the day. Several different conditions are noticed to superimpose to this general behavior, markedly in the periods 4-11 June, 28 June and 2-5 July (days 32-35), when aerosols were detected up to $5-8 \mathrm{~km}$ altitudes. In these cases backtrajectories (e.g. Sect. 4.3) together with high depolarization values reveal that these airmasses proceeded from Africa and contained dust. Most of the PBL aerosol presented some depolarization, i.e. it contained some non-spherical particles. However, a marked decrease in depolarization is observed in the period 24-31 June, mainly characterized by transport 

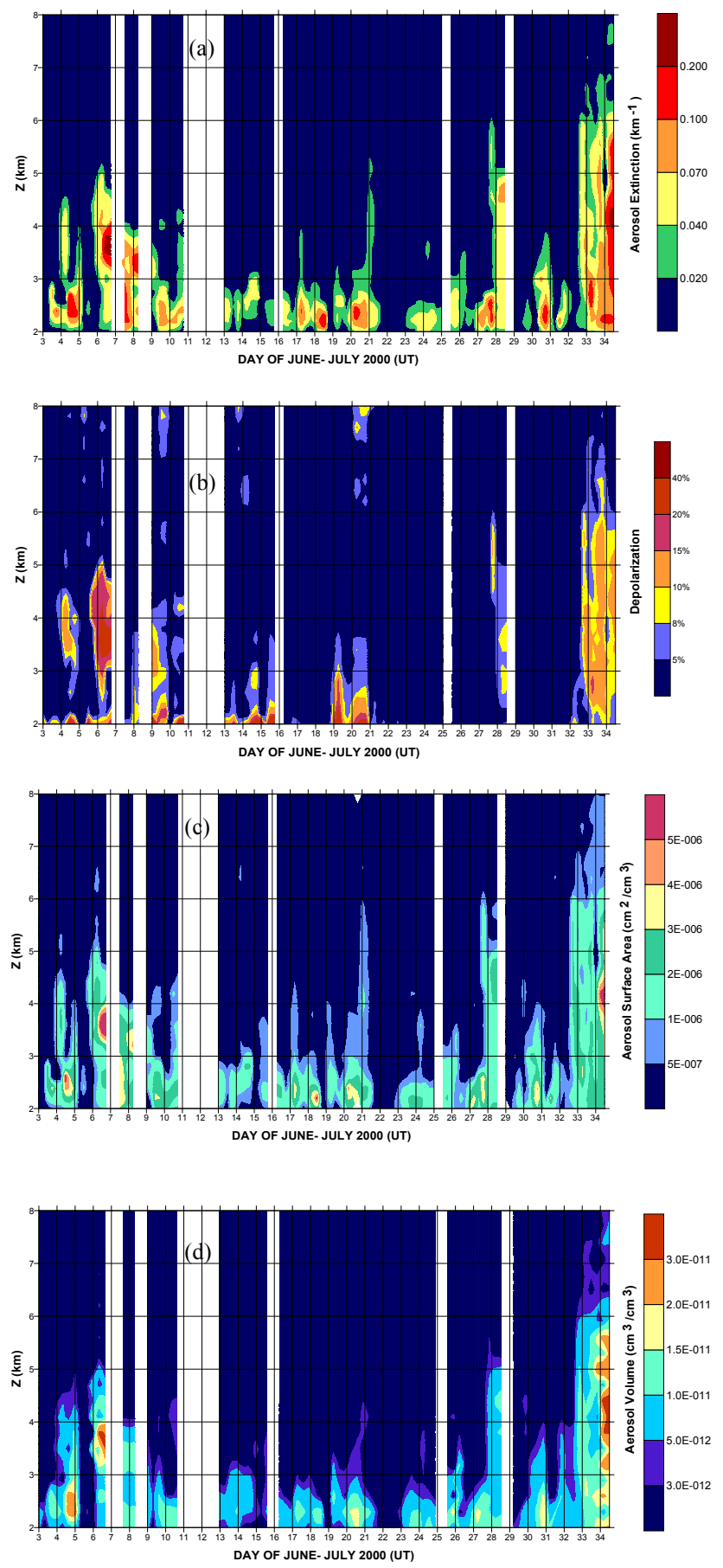

Fig. 1. Contour plots of lidar-derived aerosol properties observed during the Mt. Cimone MINATROC campaign: (a) $532 \mathrm{~nm}$ extinction coefficient $\sigma_{a}$; (b) depolarization ratio $D$; (c) surface area $S_{a}$; and (d) volume $V_{a}$.

from Western Europe. We shall further discuss these issues in Sect. 4.

Amongst the episodes of Saharan dust transport detected by VELIS, the only one reaching down to the station level was observed at the beginning of July 2000. In fact, in the period 6-9 June, when high dust was observed, aerosol extinction was comparable and depolarization was even higher than during the period 3-4 July. However, the depolarization plot of the June events (Fig. 1b) clearly shows the features of PBL and Saharan aerosols to remain separated, with most of the dust confined to levels above $3 \mathrm{~km}$, i.e. higher than the Mt. Cimone Station. This is consistent with in-situ OPC measurements, which did not indicate any significant increase in coarse particles at that time. Conversely, a progressive lowering of the dust layer clearly starts on 2 July (day 32). In fact, the arrival of mineral particles at the Station was detected in the afternoon of 3 July, well in agreement with the descent of the $8 \%$ depolarization contour at that level. This dust event reached up to about $8 \mathrm{~km}$ altitude with maximum backscatter ratio of the order of $R=5$. However, maximum values of depolarization were of the order of $D=15 \%$, i.e. much lower than the typical dry dust depolarization of $D \approx 45 \%$ (e.g. Gobbi et al., 2000), as observed between 3 and $5 \mathrm{~km}$ on 6 June. This behavior is possibly explained by the combined presence of a rather large soluble fraction (of the order of 50\%, Putaud et al., 2003) and $R H$ levels larger than $50 \%$ which could sustain the condensation of a liquid aerosol phase. As a matter of fact, cloud condensation occurred between 3 and $5 \mathrm{~km}$ altitude during the whole night between 3 and 4 July.

Plots of aerosol surface area and volume (Figs. 1c and 1d) depict a behavior similar to the one of extinction (Fig. 1a). These results show maximum values in both aerosol surface area and volume to be associated with dust events, with concentrations of the order of $500 \mu \mathrm{m}^{2} \mathrm{~cm}^{-3}$ and $30 \mu \mathrm{m}^{3} \mathrm{~cm}^{-3}$, respectively. Considering that volume is underestimated in the presence of non-spherical particles, these results indicate the dust events crossing over Mt. Cimone (that is at about $2500 \mathrm{~km}$ from the source) to be characterized by contents of at least $10-30 \mu \mathrm{m}^{3} \mathrm{~cm}^{-3}$ (that converts to approximately $25-75 \mu \mathrm{g} \mathrm{m}^{-3}$ ) extending all the way up to $6 \mathrm{~km}$ altitude. In the following section, we shall address the quality of these retrieved aerosol properties by comparing lidar observations and in situ aerosol samplings of air masses located at the Mt. Cimone Station level.

\section{Lidar-particle counters comparisons at the Mt. Ci- mone station level}

In this comparison we employ lidar retrievals for the $75 \mathrm{~m}$ height bin spanning the region 2170-2245 m a.s.l. together with size distributions observed by the DMA and OPC instruments at the Station level (2165 ma.s.l.) within $30 \mathrm{~min}$ from the lidar measurement. Size distributions are employed to compute aerosol surface area and volume, plus backscatter and extinction coefficients at the lidar wavelength of $532 \mathrm{~nm}$. These optical properties have been computed by means of a Mie scattering code at eighteen different values of the refractive index $\mathrm{m}$ (in parentheses the imaginary parts): 1.30 
Table 1. Coefficients $a$ and $b$ employed to correct for hygroscopic growth the DMA-derived aerosol size at Mt. Cimone Station. Coefficients are provided as a function of air mass origin (e.g. Sect. 4.3) and particle diameter range $\left(D_{p}\right)$, corresponding to the impactor stage number (S\#).

\begin{tabular}{ccccccccccccc}
\hline S\# & \multirow{2}{*}{$D_{p}(\mu \mathrm{m})$} & \multicolumn{2}{c}{ W-EU } & \multicolumn{2}{c}{ W-NW-EU } & \multicolumn{2}{c}{ E-EU } & \multicolumn{2}{c}{ MED } & \multicolumn{3}{c}{ AFR } \\
& & $a$ & $b$ & $a$ & $b$ & $a$ & $b$ & $a$ & $b$ & $a$ & $b$ \\
\hline 1 & $0.05-0.14$ & 0.9504 & 0.0045 & 0.8154 & 0.0057 & 0.8187 & 0.0056 & 0.8382 & 0.0054 & 0.8679 & 0.0066 \\
2 & $0.14-0.42$ & 0.7731 & 0.0078 & 0.6218 & 0.0109 & 0.5470 & 0.0126 & 0.6097 & 0.0112 & 0.8538 & 0.0073 \\
3 & $0.42-1.2$ & 0.8972 & 0.0074 & 0.6211 & 0.0111 & 0.6218 & 0.0109 & 0.6219 & 0.0110 & 0.8680 & 0.0065 \\
\hline
\end{tabular}

$(-0.0 \mathrm{i}), 1.33(-0.0 \mathrm{i}), 1.35(-0.0 \mathrm{i}), 1.4\left(-0.0 \mathrm{i},-5 \times 10^{-3} \mathrm{i}\right.$, $-0.01 \mathrm{i}), 1.45\left(-0.0 \mathrm{i},-5 \times 10^{-3} \mathrm{i},-0.01 \mathrm{i}\right), 1.50(-0.0 \mathrm{i}$, $\left.-5 \times 10^{-3} \mathrm{i},-0.01 \mathrm{i}\right), 1.55\left(-0.0 \mathrm{i},-5 \times 10^{-3} \mathrm{i},-0.01 \mathrm{i}\right)$ and $1.60\left(-0.0 \mathrm{i},-5 \times 10^{-3} \mathrm{i},-0.01 \mathrm{i}\right)$. These values have been selected to represent the full variability range of aerosol composition from pure water droplets $(m=1.33-0.0 \mathrm{i})$ to mineral dust grains $m=1.55-0.01$ i (e.g. d'Almeida et al., 1991). The boundary values $m=1.30-0.0 \mathrm{i}$ and $m=1.60$ have been included to check for results outside the expected range. Use of the Mie theory implies considering particles as spherical. While such an assumption is rather good in the case of liquid and of hygroscopic aerosols, it might lead to a strong overestimation of backscatter and to a slight underestimation of extinction in the case of non-spherical particles as soot or mineral dust (Mishchenko et al., 1997; Gobbi et al., 2002). As mentioned, we shall use a non-spherical scattering model to invert lidar traces of Saharan dust and a spherical scattering model for continental aerosols. Nevertheless, we shall use lidar depolarization information to flag possible sources of inconsistencies by indicating when non-spherical particles are affecting the signal.

\subsection{RH-correction of observed particle size}

Size distributions employed in this analysis are obtained from DMA data up to $500 \mathrm{~nm}$ diameters and OPC data above that size. Since DMA size distributions are provided for dry particles, physical and optical properties computed using these size distributions should be converted to ambient conditions to allow for comparison with lidar data. To account for such an effect, we have used a semi-empirical hygroscopic growth model parameterized by using the Köhler theory and size-resolved measurements (from impactor filters) of chemical composition of the aerosol (Putaud et al., 2003). Impactor filters were collected at the same location as the other in situ measurements. The hygroscopic growth model considered in the present study relates the wet aerosol diameter $D_{\text {wet }}$ at a given ambient relative humidity $R H$ (measured at the station) to the dry aerosol diameter $D_{\text {dry }}$ by means of an expression of the form: $D_{\text {wet }}=D_{\text {dry }} a \exp \left(b^{*} R H\right)$, where $R H$ is expressed in \% and $a, b$ are constants depending on the particle size and chemical composition. Analysis of the chemical composition of aerosols, in particular for water sol- uble inorganic and organic species, shows important changes in both the percentage and the ionic composition from one air mass to the other, as well as from one size range to another within the same air mass. Therefore, for each air mass type (e.g. Sect. 4.3) we have determined different constants $a$ and $b$ (reported in Table 1) for each Berner impactor stage by fitting the mean wet aerosol diameter computed by the Köhler theory as a function of relative humidity. At a given relative humidity, the mean wet aerosol diameter of a given impactor stage then represents the mean of the wet diameters computed by means of the Köhler theory from the DMA dry diameter measurements enclosed in that stage. In the present calculations, the aerosol in the DMA size range was assumed to be internally mixed, with mean chemical composition corresponding to the one observed in the relevant impactor stage and for the specific air mass. The variation of the surface tension with concentration of moles of carbon (Facchini et al., 1999) was also considered.

All size distribution-derived physical quantities (i.e. surface area, volume, backscatter and extinction coefficients) have been computed for both $R H$-corrected and non corrected size distributions. Results of these computations and their comparisons with lidar retrievals obtained at the most $30 \mathrm{~min}$ apart from the size distribution measurement are discussed hereafter.

4.2 Backscatter and extinction: sensitivity to $R H$ and refractive index

Minimum and maximum backscatter coefficients obtained from Mie calculations are reported in Fig. 2a for non corrected data and in Fig. $2 \mathrm{~b}$ for $\mathrm{RH}$-corrected data, respectively. Both figures show backscatter coefficients to sharply increase when switching from lower ( $m=1.33-0.0 \mathrm{i})$ to higher value $(m=1.55-0.0 \mathrm{i})$ of the refractive index. Lidar-measured backscatter coefficients are also plotted in these figures as black dots. Comparison of Figs. $2 \mathrm{a}$ and $2 \mathrm{~b}$ clearly shows that an agreement between lidar and size distribution-derived aerosol backscatter is only achieved when the $R H$-correction is applied. In this case most of the lidar observations fall within the backscatter range determined by refractive index variability. This result is quantified by the analysis of 

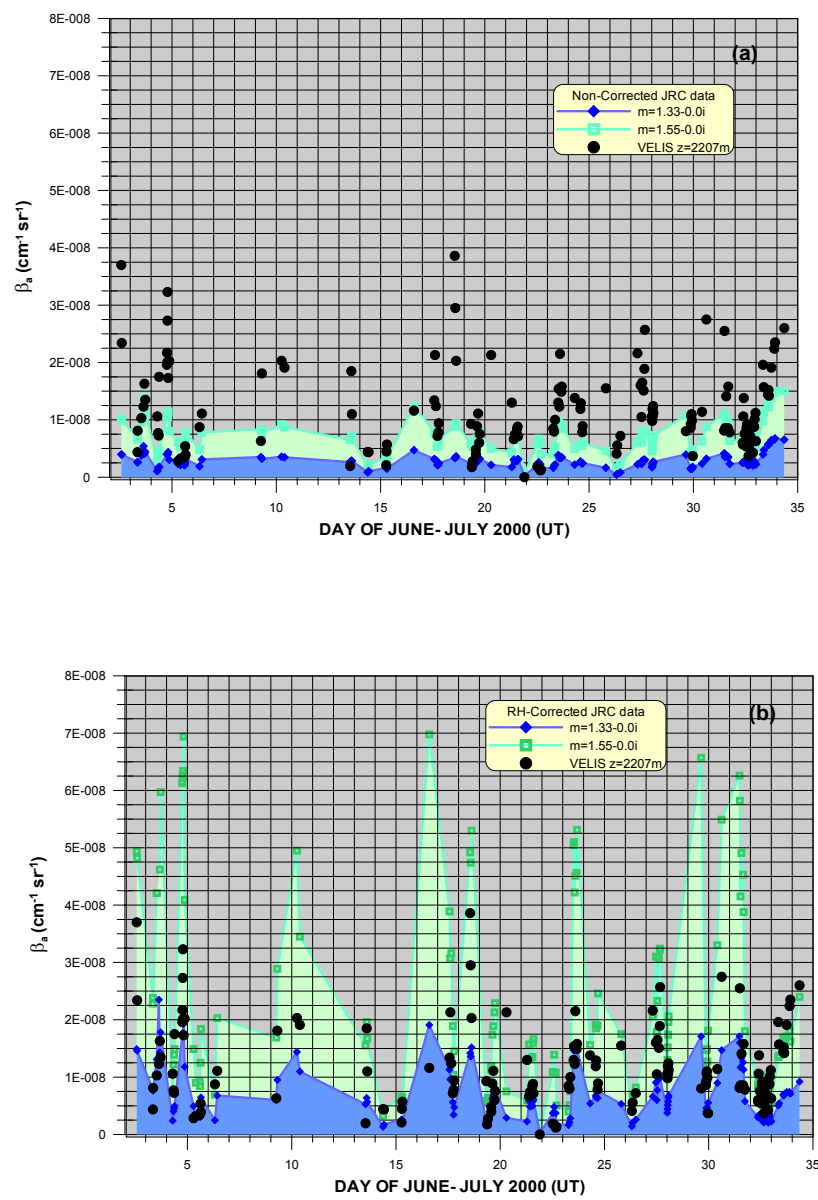

Fig. 2. Lidar observed (black dots) and size distribution-derived backscatter coefficients for two values of the refractive index:1) $m=1.33-0.0 \mathrm{i}$ (diamonds), 2) $m=1.55-0.0 \mathrm{i}$ (open squares). Results employing original DMA "dry" size distributions are presented in(a), while (b) considers particles $R H$-dependent growth.

average, module relative differences:

$d \beta_{a} / \beta_{a}=N^{-1} \sum_{i=1, N}\left(\left|\beta_{\mathrm{VELIS}_{i}}-\beta_{\mathrm{JRC}_{i}}\right| / \beta_{\mathrm{JRC}_{i}}\right)$

computed for the eighteen values of the refractive index ( $N=148$ being the number of considered measurements). The behavior of $d \beta_{a} / \beta_{a}$ versus $m$ is reported in Fig. 3 . This plot shows that minimization of $d \beta_{a} / \beta_{a}$ for non $R H$ corrected data is only achieved by forcing $\mathrm{m}$ to large, unrealistic values. Conversely, the $R H$-corrected dataset reaches a minimum of $d \beta_{a} / \beta_{a}=0.38$ for $m=1.45-0.0 \mathrm{i}$, while smoothly increasing for both smaller and larger values of $m$. As expected, Fig. 3 shows that the effect of a non-zero imaginary part of the refractive index is to reduce backscatter, an effect that could be also obtained by a smaller real refractive index with zero absorption. Refractive indices retrieved in the following analysis should then be interpreted accordingly.

Values of $d \beta_{a} / \beta_{a}$ are representative of the combined average relative indetermination of the two measurements. In this

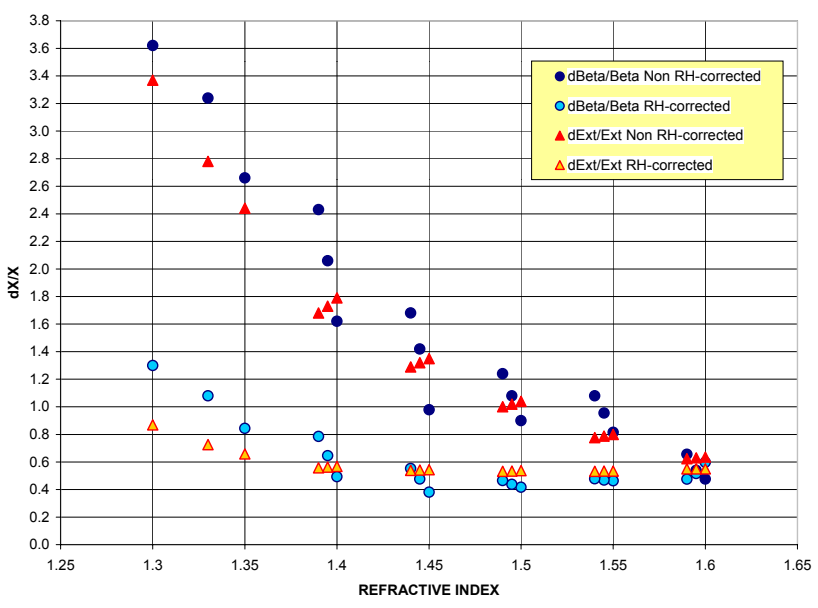

Fig. 3. Dependence on choice of the refractive index $m$ (non-zero imaginary components are represented by a corresponding decrease in the real part) of the relative differences $d \beta_{a} / \beta_{a}$ (blue circles for non- $R H$-corrected data, pale blue circles for $R H$-corrected data) and $d \sigma_{a} / \sigma_{a}$ (red triangles for non- $R H$-corrected data, orange triangles for $R H$-corrected data), averaged over the whole data set.

respect, even though levels of $d \beta_{a} / \beta_{a}=38 \%$ can appear quite large, we should consider that this is the agreement to expect when employing a single, average refractive index $(m=1.45$ $0.0 \mathrm{i})$ for the whole campaign. In Sect. 4.3 , for each $\mathrm{i}^{\text {th }}$ measurement we shall minimize with respect to $\mathrm{m}$ the differences $d \beta_{i}(m)$ to provide an estimate of the refractive index specific to the relevant aerosol type. The statistical significance of this retrieval will be addressed in that section.

The behavior of extinction coefficients average differences $d \sigma_{a} / \sigma_{a}$ as a function of $m$ is also reported in Fig. 3. Similarly to backscatter, minimization of $d \sigma_{a} / \sigma_{a}$ for non $R H$ corrected data is only reached by increasing the refractive index to unrealistic values. Conversely, when applying RHcorrection a broad region of minimum average differences $d \sigma_{a} / \sigma_{a} \approx 0.55$ is found for refractive indices ranging between 1.45 and 1.55 . These results show extinction retrievals to be consistent with backscatter ones, but less sensitive to a precise choice of the refractive index. In Sect. 4.3 we shall see how the $d \beta_{a} / \beta_{a}$ minimization procedure carried-out to retrieve a time-dependent value of $m$ will also improve the agreement of the extinction retrievals and provide an estimate of the related errors.

As a campaign average, approximately $20 \%$ of all aerosol backscatter and extinction coefficients computed from the $R H$-corrected size distributions were generated by particles smaller than $0.15 \mu \mathrm{m}$ in radius. Only a few percent of $\beta_{a}$ and $\sigma_{a}$ was due to particles larger than $1 \mu \mathrm{m}$ in the case of continental aerosols. Conversely, in the presence of Saharan dust (whose grains were mainly larger than $1 \mu \mathrm{m}$ ) this latter fraction increased to approximately $20 \%$ for extinction and $40 \%$ for backscatter. These results reveal two noteworthy points: 1) the importance of resolving aerosol size 

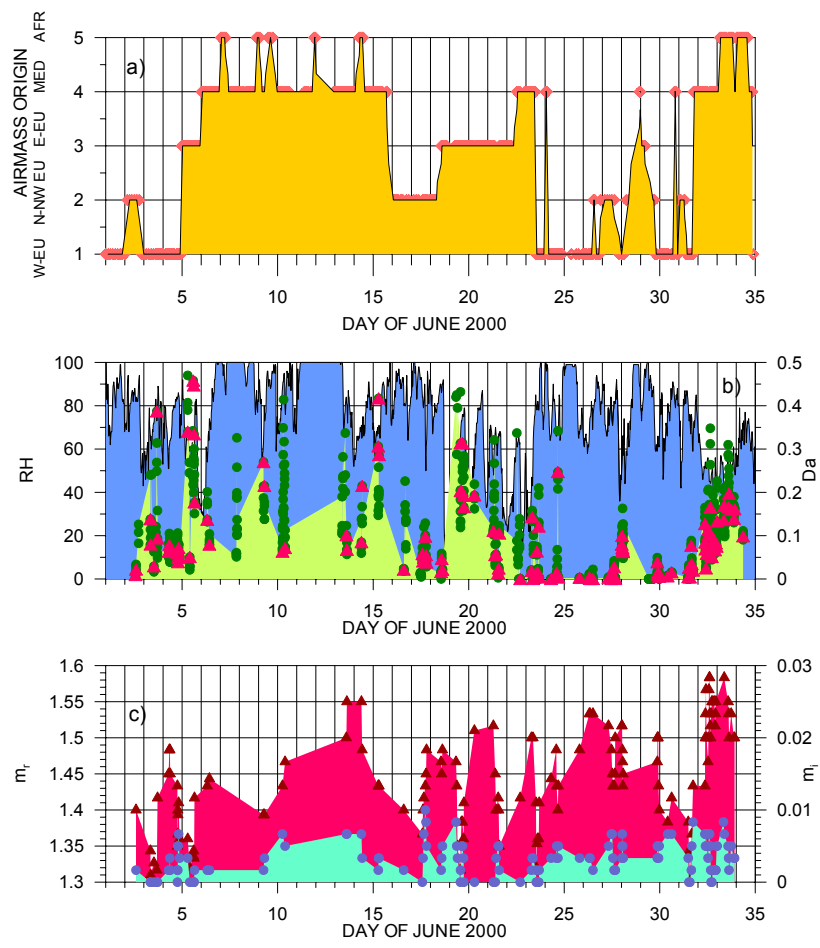

Fig. 4. Time evolution of: (a) origin of air masses arriving at Mt. Cimone Station level during the MINATROC campaign; (b) relative humidity $R H$ (black line, blue filling) and aerosol depolarization $D_{a}$ (green dots represent all lidar data, while red triangles show data retrieved within $30 \mathrm{~min}$ from is situ observations, at $\mathrm{RH}<90 \%$ ), and (c) three-point running averages of real $m_{r}$ (red triangles) and imaginary part $m_{i}$ (blue bullets) part of the aerosol refractive index, as inferred from minimization of lidar and size distribution-derived backscatter coefficients.

distributions below $0.15 \mu \mathrm{m}$ (a typical lower threshold of optical particle counters) when evaluating aerosol optical properties, and 2) the error (overestimate) intrinsic to the Miecomputed backscatter in the case of non-spherical particles can be rather large and tending to compensate the possible lack of information about smaller sizes mentioned at point (1).

4.3 Airmass origin in relation to depolarization and refractive index

To improve the interpretation of results we plotted in Fig. 4a the origin of the airmasses arriving at Mt. Cimone Station (2165 m a.s.1.), as obtained by 10-day, three-dimensional backtrajectories computed by the FLEXTRA model (Stohl and Wakowa, 1995). These were classified into five categories according to the geographical area of longer permanence while approaching Mt. Cimone. This backtrajectory information has been parameterized by indicating with 1 air from West Europe, with 2 air from N-NW Europe, with 3 air from Eastern Europe, with 4 air from the Mediterranean

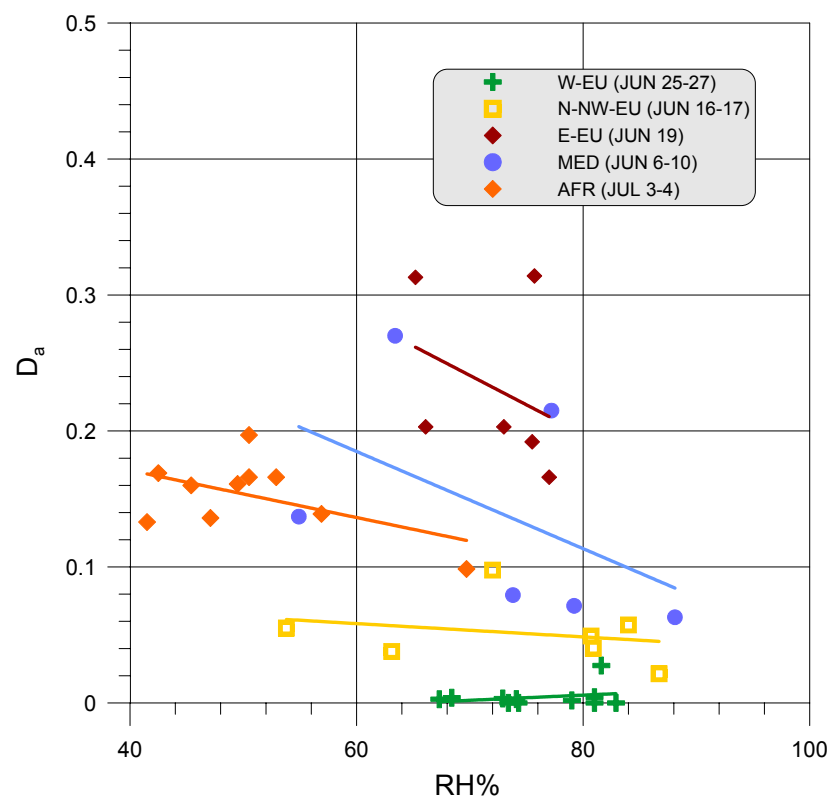

Fig. 5. Relationship between $D_{a}$, and $R H$ at Mt. Cimone Station level, for selected periods corresponding to airmasses proceeding from the five regions considered: 1) W-Europe (green crosses); 2) N-NW Europe (open orange squares); 3) E-Europe (purple diamonds); 4) Mediterranean (blue bullets) and 5) Africa (orange diamonds).

basin and with 5 air from Africa. This plot shows that airmasses originated from the Mediterranean-African regions in the periods 6-15 June and 2-5 July 2000 . The remaining periods were characterized by air mainly proceeding from Eastern Europe (5 June and 19-22 June) and Western Europe (3-4, 24-27 and 30 June). In Fig. 4b we plot the relative humidity $(R H)$ record as measured at the Station level (P. Bonasoni, personal communication, 2001), together with the aerosol depolarization ratio $D_{a}$, observed by VELIS at that level.

\subsubsection{Depolarization}

A first analysis of Figs. $4 \mathrm{a}$ and $4 \mathrm{~b}$ shows lower values of depolarization to be mainly linked to airmassess arriving from Western and N-NW Europe, an effect particularly evident in the period 2-5 and 25-31 June. Conversely, air from EEurope was characterized by relatively high values of depolarization, as well as air proceeding from the Mediterranean and African regions. The relationship between $D_{a}$ and $R H$ for selected periods, corresponding to airmasses proceeding from these five regions is presented in Fig. 5. For these five airmasses, average values of aerosol composition as observed at Mt. Cimone Station by chemical analysis of the sub and super-micron aerosol modes (Putaud et al., 2003) are reported in Table 2, together with average aerosol depolarization. In Fig. 5, the low-depolarization airmasses of 2527 June (from W Europe) and of 16-17 June (from N-NW 
Table 2. Aerosol properties averaged over time periods when airmasses had homogeneous origin: 1) Aerosol depolarization $D_{a}$ plus average volume fraction (standard deviation in parentheses) of aerosol components: 1) Soluble; 2) Black Carbon, (BC); 3) Refractory (dust+nonvolatile organic carbon); 4) Non-soluble (semi-volatile). Npts. indicates number of employed measurements.

\begin{tabular}{cccccccc}
\hline Time period & Air origin & $D_{a}$ & Soluble & BC & Refractory & Non-soluble & Npts. \\
\hline 25-27 June & W-EU & 0.00 & $0.35(0.06)$ & $0.03(0.01)$ & $0.08(0.03)$ & $0.54(0.08)$ & 22 \\
16-17 June & N-NW-EU & 0.06 & $0.51(0.04)$ & $0.02(0.00)$ & $0.10(0.05)$ & $0.37(0.05)$ & 17 \\
19 June & E-EU & 0.24 & $0.46(0.10)$ & $0.05(0.03)$ & $0.18(0.08)$ & $0.31(0.19)$ & 24 \\
6-10 June & MED & 0.17 & $0.65(0.18)$ & $0.02(0.01)$ & $0.07(0.02)$ & $0.26(0.19)$ & 73 \\
3-4 July & AFR & 0.15 & $0.53(0.13)$ & $0.03(0.01)$ & $0.23(0.05)$ & $0.21(0.12)$ & 34 \\
\hline
\end{tabular}

Europe) do not show any significant correlation with $R H$, i.e. a liquid phase characterizes these aerosols already at $50 \%$ $R H$. Much higher depolarization levels and solubility effects (decrease of $D_{a}$ with increasing $R H$ ) are instead observed for East Europe (19 June), Mediterranean (6-11 June) and African aerosols (3-4 July).

Saharan dust is commonly considered to be hydrophobic. This property is well portrayed by the airborne observations of aerosol extinction coefficients carried-out in dry ( $R H=10-30 \%)$ and wet $(R H=80-90 \%)$ conditions by Gasso et al. (2000). Those measurements showed the marine PBL aerosol extinction to grow by a factor of 2-3, when switching from the dry to the wet conditions. Conversely, the extinction coefficient of Saharan dust showed no meaningful increase when subject to the same change in $R H$. Nevertheless, at the Mt. Cimone Station level we observed low aerosol depolarization (average $D_{a}<20 \%$ ) and an anticorrelation between $D_{a}$ and $R H$ ( $R H$ ranging between 40 and $70 \%$ ) even in the Saharan aerosol conditions of 3-4 July (Fig. 5). In fact, in situ observations at $2165 \mathrm{~m}$ reveal the soluble fraction of these airmasses (e.g. Table 2) to be larger than the campaign average and to peak at noon of 3 July, when PBL convection reaches its maximum. As opposed to this behavior, after 12:00 UT of 3 July aerosol depolarization was observed to reach the typical dry dust value $D_{a} \approx 45 \%$ at levels above $2.8 \mathrm{~km}$, i.e. in the region less affected by intrusions of PBL aerosols. All this evidence points out to the presence of a soluble aerosol fraction, externally mixing with the Saharan dust particles at the Mt. Cimone Station level. It is worth noticing that the same conclusion is independently reached by Putaud et al. (2003) on the basis of chemical analysis of the sub and super-micron aerosol modes.

\subsubsection{Refractive index}

To estimate the time-dependent aerosol refractive index, we determined the $m$ value (amongst the eighteen ones previously reported) minimizing the $d \beta_{a_{i}} / \beta_{a_{i}}$ ratio for each $i^{\text {th }}$ lidar-in situ comparison. Three-point running averages of the real and imaginary parts of the refractive index as retrieved by this procedure are reported in Fig. 4c. This plot shows that until 17 June (with the exception of the possi- bly African air of 13-14 June), the retrieved $m$ values are rather low, mainly $m<1.45-0.005$ i. The aerosol refractive index then grows during the second part of the campaign, peaking in both its real and imaginary parts $(m \approx 1.5-0.005 i)$ for the liquid (non-depolarizing) particles from Western and NW Europe (25-27 June) and during the Saharan dust event of 2-4 July, when it varies about the typical values for dust $(m \approx 1.55)$.

To evaluate the statistical significance of the refractive index retrievals, we computed the $d \beta_{a} / \beta_{a}$ parameter (Eq. 1) for the five homogeneous airmasses defined in Table 2. For each airmass, computations were carried-out employing all the eighteen $\mathrm{m}$ values of this study. The resulting average $d \beta_{a} / \beta_{a}$ (and relevant standard deviation, STD) are plotted as a function of $\mathrm{m}$ in Fig. 6. For the Western European aerosols of 25-27 June (Fig. 6a), $d \beta_{a} / \beta_{a}$ reaches a sharp minimum in the $m=1.50-0.0 \mathrm{i}-1.55-0.0 \mathrm{i}$ region. Associated small standard deviations both indicate this aerosol to be homogeneous over the three days and support the statistical significance of the refractive index retrieval. In fact, all points below $m=1.45-0.0 \mathrm{i}$ and above $m=1.55-0.0 \mathrm{i}$ fall outside the STD of $d \beta_{a} / \beta_{a}$ at $m=1.5-0.0 \mathrm{i}$. The large non-soluble, semi-volatile fraction of this aerosol (e.g. Table 2), together with its liquid phase $(D \approx 0 \%)$ induce to believe this is an organic aerosol, possibly containing toluene or benzene compounds, whose typical refractive indices span the range 1.47-1.59.

N-NW Europe aerosols of 16-17 June (Fig. 6b) show a minimum in both $d \beta_{a} / \beta_{a}$ and its standard deviation in the $m=1.40-0.0 \mathrm{i}-1.45-0.01 \mathrm{i}$ region. However, standard deviations indicate that a broader region, encompassing refractive indices up to $m=1.55-0.005 \mathrm{i}$ could characterize this airmass. In fact, this aerosol shows a pretty large non-soluble, semivolatile fraction (e.g. Table 2). Eastern Europe aerosols of 19 June (Fig. 6c) present a minimum in both $d \beta_{a} / \beta_{a}$ and its standard deviation at $m=1.45-0.0 \mathrm{i}$. The broad region of $d \beta_{a} / \beta_{a}$ values falling within the STD of that minimum indicate that all refractive indices larger than $m=1.40-0.01 \mathrm{i}$ could characterize this aerosol. It is interesting to note that this airmass shows the largest values of $D_{a}$ and of $-d D_{a} / d R H$ (e.g. Fig. 5). Such behavior is likely due to the big refractory and soluble fractions coexisting in these aerosols (e.g. 
Table 2). In fact, the effect of a soluble fraction is of decreasing both its depolarization and refractive index while diluting. Both the large refractive index variability of Fig. $4 \mathrm{c}$ and the broad region of minimum $d \beta_{a} / \beta_{a}$ of Fig. $6 \mathrm{~d}$ can then be explained by these properties. The $d \beta_{a} / \beta_{a}$ minimum for Mediterranean aerosols (6-11 June, Fig. 6d) is reached at $m=1.45-0.005 i$. Conversely, smallest standard deviations are found at $m=1.55-0.01 \mathrm{i}$. Therefore, the $m=1.40-0.0 \mathrm{i}-$ $1.60-0.01 \mathrm{i}$ region provides possible values of this airmass refractive index. As for the E-Europe aerosol, this airmass shows pretty large $D_{a},-d D_{a} / d R H$ and soluble component values (e.g. Fig. $6 \mathrm{~d}$ and Table 2). Again, this would explain the broad range of possible $\mathrm{m}$ values for this 5-day period as mainly due to solubility effects.

In spite of the large refractory fraction of its aerosols, the Saharan airmass of 3-4 July also contains a large soluble fraction (e.g. Table 2). This explains both the refractive index variability observed in this period (Fig. 5) and the somewhat broad region of minimum $d \beta_{a} / \beta_{a}$ observed in Fig. 6e. Nevertheless, this region is centered about $m=1.53$, the typical refractive index of dust, and mainly zero-absorption $m$ values (1.45-0.0i, 1.50-0.0i and 1.55-0.0i) fall within the STD bar of the minimum $d \beta_{a} / \beta_{a}$ found at $m=1.6-0.01$ i.

In the previous analysis, best results (an uncertainty $d m=0.05$ over a three-day average) were achieved for air containing liquid aerosol with low $R H$ dependence (i.e. with small soluble fraction). Conversely, aerosols with larger soluble fraction (East Europe, Mediterranean and African) led to proportionally more spread retrievals, mostly linked to short-term $R H$ changes. Overall, these results are in support of the statistical significance of the refractive index retrievals presented in Fig. 4. The latters are also in good agreement with the long term aerosol climatology collected by the photometer network AERONET and described in Dubovik et al. (2002).

\subsection{Closure analysis}

The methods employed in the previous sections can be summarized as follows: from the VELIS lidar we have retrieved $\beta_{\text {VELIS }}, \sigma_{\text {VELIS }}(\beta), S_{\text {VELIS }}(\beta)$, and $V_{\text {VELIS }}(\beta)$. The insitu size distribution measurements yielded measured $S_{\mathrm{JRC}}$, $V_{\mathrm{JRC}}$, whereas application of a Mie code to these size distributions (with "tunable" refractive indices) provided a set of eighteen estimates of $\beta_{\mathrm{JRC}}$ and $\sigma_{\mathrm{JRC}}$. Then, differences for each backscatter measurement pair ( $\left.\beta_{\mathrm{VELIS}}, \beta_{\mathrm{JRC}}\right)$ recorded within $30 \mathrm{~min}$ have been minimized to determine the associated best refractive index $m$. Now, to evaluate the outcomes of such a minimization, and to assess the quality of the lidar-derived extinction, surface area and volume retrievals, we shall address mean values of the relevant absolute (e.g. Eq. 1) and sign-conserving (bias) differences between the lidar-derived and the in-situ retrieved variables. The time evolution of aerosol extinction $\sigma_{a}$, surface area $S_{a}$ and volume $V_{a}$ as estimated from lidar and obtained from in situ
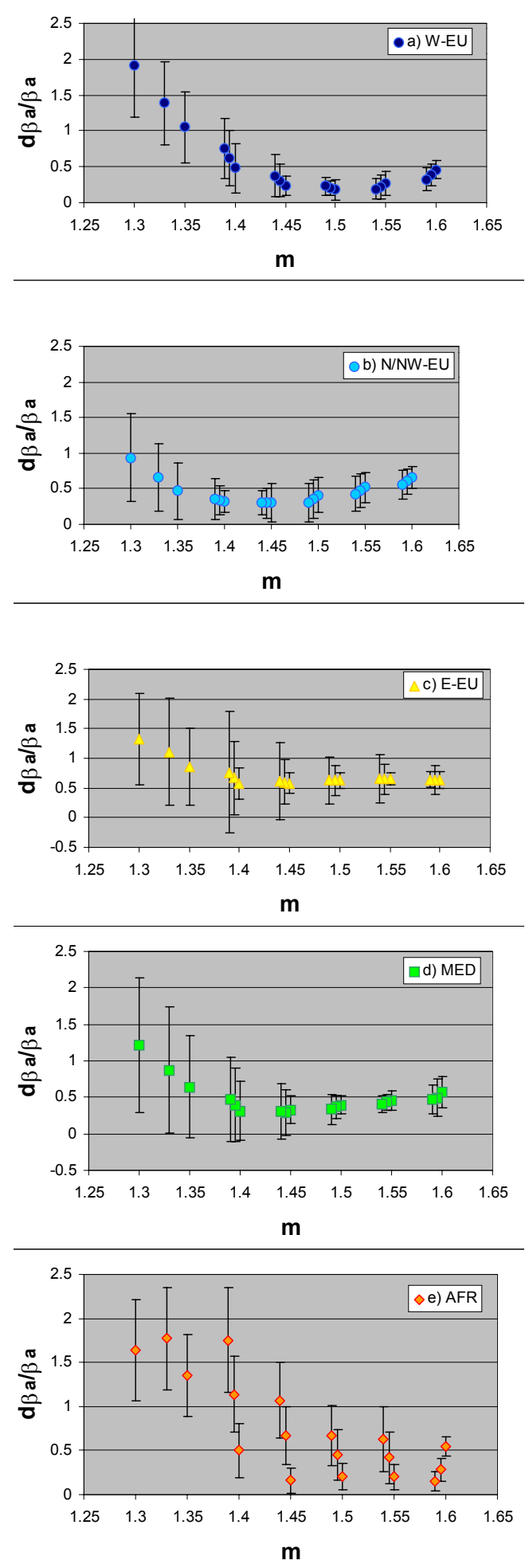

Fig. 6. Average values of $d \beta_{a} / \beta_{a}$ (error bars representing relevant standard deviations) computed for the five homogeneous-origin airmasses defined in Table 2, and plotted as a function of the eighteen values of refractive index considered in this study (non-zero imaginary components are represented by a corresponding decrease in the real part). Single plots correspondence: (a) W-Europe; (b) N-NW Europe; (c) E-Europe; d) Mediterranean, and e) Africa. 
Table 3. Absolute values of average relative differences as of Eq. (1) (in parentheses the sign-conserving relative differences, i.e. bias) between lidar and size distribution-derived aerosol properties. Three periods are addressed: 1) the whole campaign (2 June-4 July), 2 ) the "continental aerosol period (2 June-2 July at 00:00) and 3) the African dust period (2 July at 00:00-4 July at noon). Backscatter and extinction coefficient differences are obtained after minimization of $d \beta_{a}$ with respect to refractive index.

\begin{tabular}{cccccc}
\hline Time period & $d \beta_{a} / \beta_{a}$ & $d \beta_{a} / \beta_{a}$ & $d S_{a} / S_{a}$ & $d V_{a} / V_{a}$ & Npts. \\
\hline 2 June-4 July & $0.05(-0.01)$ & $0.36(-0.18)$ & $0.41(-0.16)$ & $0.37(-0.23)$ & 148 \\
2 June-2 July & $0.06(-0.02)$ & $0.40(-0.28)$ & $0.42(-0.28)$ & $0.43(-0.29)$ & 116 \\
2 July-4 July & $0.04(+0.01)$ & $0.23(+0.16)$ & $0.35(+0.22)$ & $0.17(-0.01)$ & 32 \\
\hline
\end{tabular}

measurements (both $\mathrm{RH}$-corrected and non corrected data) is reported in Figs. 7a, $7 \mathrm{~b}$ and $7 \mathrm{c}$, respectively. Similarly to the case of $\beta_{a}$, these results show that $R H$-corrected data provide a better agreement between lidar and in situ data. Three different time intervals will be considered in the comparative analysis of lidar and in-situ retrievals: 1$)$ the whole campaign, 2 June-4 July (148 data points); 2) the "continental" period 2 June-2 July (116 data points) and 3) the Saharan dust period, 2-4 July (32 data points). Relevant results reported in Table 3 show that minimization with respect to $m$, led to a decrease in average backscatter differences $d \beta_{a} / \beta_{a}$ from 0.38 (resulting from a single, best value of $\mathrm{m}$, e.g. Sect. 4.2) to 0.05 for the whole campaign period, and to $d \beta_{a} / \beta_{a}=0.04$ in dust conditions. Systematic differences in these two periods are -0.01 and +0.01 , respectively (e.g. Table 3$)$. These values indicate that, in spite of the finite number of employed refractive indices (18), the minimization led to a good agreement between the two data sets.

The minimization process carried-out for backscatter leads to average extinction differences $d \sigma_{a} / \sigma_{a}=0.36$ for the whole period (e.g. Table 3). In the analysis using a fixed, "best" refractive index $(m=1.45$, Sect. 4.2) this value was $d \sigma_{a} / \sigma_{a}=0.55$ for $R H$-corrected data and 0.67 for non- $R H$ corrected data. Again, the agreement is better during the Saharan dust event $\left(d \sigma_{a} / \sigma_{a}=0.23\right)$ than during the "continental" period $\left(d \sigma_{a} / \sigma_{a}=0.40\right)$. The systematic difference observed during the latter period $(-0.28)$ becomes smaller and positive $(+0.16)$ in dust conditions. Such a switch is likely due to an underestimation of $\sigma_{a}$ by the spherical continental aerosol model applied to lidar observations when in the presence of non-spherical particles, and to an overestimation of $\sigma_{a}$ caused by use of the non-spherical dust model in the presence of mixed liquid-dust particles. Overall, the non-spherical (dust) model performs better than the spherical (continental aerosol) one. However, considering that the average relative error expected in the lidar estimation of $\sigma_{a}$ is of the order of 0.25 for continental aerosols and of 0.40 for Saharan dust (e.g. Sect. 2.1), even the largest average absolute differences reported above $\left(d \sigma_{a} / \sigma_{a}=0.40\right)$ fall within the combined error bars of the VELIS and JRC measurements (of the order of $16 \%$, e.g. Sect. 2.2).
Surface area and volume average differences for the whole campaign decrease from $d S_{a} / S_{a}=0.60$ and $d V_{a} / V_{a}=0.66$ in the non $R H$-corrected record down to 0.41 and 0.37 for the $R H$-corrected data. Again, the agreement improves during the dust event (e.g. Table 3). It is worth noticing that while for surface area (extinction) systematic differences switch from $-0.28(-0.28)$ in continental aerosol conditions to $+0.22(+0.16)$ in dust conditions, in the case of volume the change is much smaller (from -0.29 to -0.01 ). Results then indicate a better performance of the non-spherical dust model with respect to the continental one also in the case of surface area and volume retrievals. At the same time, the spherical dust model employed in the volume estimates performs very well, confirming the effects of a mixed (liquid plus solid) phase of aerosols at the Station level during that event. Taking into account that the average uncertainty expected in the lidar estimation of $S_{a}\left(V_{a}\right)$ is of the order of 0.30 $(0.40)$ for continental aerosols and of 0.45 (0.80) for Saharan dust (e.g. Sect. 2.1), even the largest average absolute differences found in this analysis $\left(d S_{a} / S_{a}=0.42, d V_{a} / V_{a}=0.43\right)$ fall within the combined error bars of the VELIS and JRC measurements (of the order of $22 \%$ (29\%), e.g. Sect. 2.2).

\section{Conclusions}

Aerosol extinction, depolarization, surface area and volume profiles obtained by lidar during the MINATROC campaign at Mt. Cimone (1 June-5 July 2000) have been presented. These observations consistently show the presence of a daily, PBL-related aerosol cycle reaching approximately $3 \mathrm{~km}$ altitude. Transport of Saharan dust was also observed to occur in several occasions, reaching up to $8 \mathrm{~km}$ altitude. However, lidar depolarization profiles indicate that during the month of June the dust did not reach down to the Mt. Cimone Station level (2165 ma.s.1.), where the campaign in situ sampling took place. Conversely, a dust event first observed by lidar on 2 July is shown to extend well down to the station level by the afternoon of 3 July, when it also started being detected by the instrumentation deployed there.

To perform a closure analysis, aerosol size distributions observed at the Mt. Cimone Station by DMA and OPC instruments have been employed to compute aerosol 
backscatter and extinction coefficients plus surface area and volume. These values have then been compared to retrievals of the same variables as obtained by the VELIS lidar in the corresponding height interval 2170-2245 m. For each measurement, minimization of differences between the lidar and the particle counters backscatter coefficients (the latters obtained for eighteen values of the refractive index), was shown to provide a statistically significant value of the refractive index $\mathrm{m}$ for the relevant aerosol. When using such a refractive index, average differences (whole campaign) between lidar and in situ-retrieved backscatter and extinction coefficients are of $5 \%$ and $36 \%$, respectively. In the case of surface area and volume, average differences are of the order of $41 \%$ and $37 \%$, respectively (e.g. Table 3). All these values fall well within the combined uncertainty of the lidar and in situ retrievals. It was also noticed that all average differences reduced during the July dust event, a case for which a non-spherical scattering model was available to invert the lidar signal. Conversely, in continental aerosol conditions (when a spherical aerosol model was employed) average differences were observed to increase with depolarization, i.e. with increasing particles non-sphericity. These results show how sensitive to particles shape the quantitative retrieval of aerosol properties by means of optical methods can be. In this context, lidar depolarization measurements were confirmed to be a very useful tool for recognizing which aerosol shape (that is thermodynamic phase) is being observed and what inversion model to adopt.

By also exploiting air mass back-trajectories, together with the relative humidity record and aerosol chemical analysis (for the Station level) we showed that during the campaign: 1) Western and N-NW Europe aerosols were less soluble and more liquid than Eastern European and Mediterranean ones; 2) Saharan dust was likely externally mixed with a large amount of soluble aerosols; 3 ) aerosol depolarization $D_{a}$ was correlated with the refractory content of the aerosol, while $-d D_{a} / d R H$ was correlated with its soluble fraction (aerosol depolarization $D_{a}$ and relative humidity $R H$ were generally anticorrelated, with the exception of the West and NWEuropean pollution aerosols); and 4) the retrieved refractive indices were positively correlated with the non-soluble and refractory aerosol fraction (non-volatile organic carbon and dust, respectively) observed at Mt. Cimone Station (Putaud et al., 2003).

On the whole, the analysis presented here provides a good (well within the inversion model error bars) in situ validation of the single wavelength lidar estimates of aerosol extinction, surface area and volume. When considered together with the validation of lidar-retrieved optical depth observations (Gobbi et al., 2002; Barnaba and Gobbi, 2003), these results show the great potential elastic backscatter, polarization-sensitive lidars have for reducing the current lack in knowledge affecting the altitude-dependent properties of atmospheric aerosols.
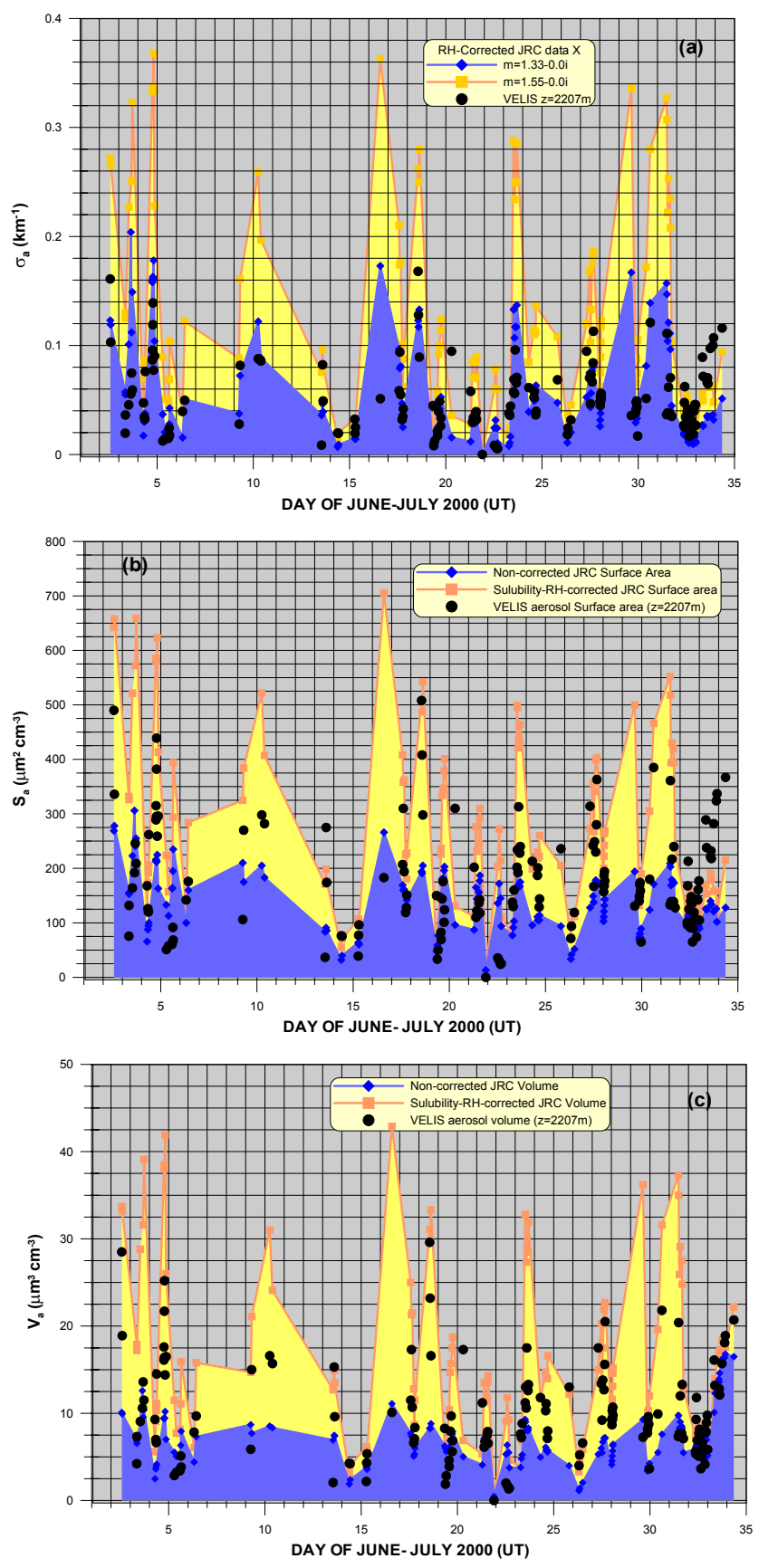

Fig. 7. Comparison of lidar (black dots) and size distributionderived parameters as observed at the level of the Mt. Cimone Station during the MINATROC campaign: (a) $532 \mathrm{~nm}$ aerosol extinction $\sigma_{a}$ (diamonds and squares represent results for $m=1.33-0.0 \mathrm{i}$, and $m=1.55-0.0 \mathrm{i}$, respectively), (b) aerosol surface area $S_{a}$, and (c) aerosol volume $V_{a}$. In the case of $S_{a}$ and $V_{a}$ diamonds represent non $R H$-corrected DMA data, while squares consider data after hygroscopic growth.

Acknowledgements. This work has been carried out under the European Union Contract EVK2-CT-1999-00003 "MINATROC". We wish to thank P. Bonasoni and F. P. Calzolari for the support provided during the Mt. Cimone campaign. 


\section{References}

Balkanski, Y., Bauer, S. E., van Dingenen, R., Bonasoni, P., Schulz, M., Fischer, H., Gobbi, G. P., Hanke, M., Hauglustaine, D., Putaud, J. P., Stohl, A., and Raes, F.: The Mt. Cimone, Italy, free tropospheric campaign: principal characteristics of the gaseous and aerosol composition from European pollution, Mediterranean influences and during African dust events, Atmos. Chem. Phys. Discuss., 3, 1753-1776, 2003.

Barnaba, F. and Gobbi, G. P.: Lidar estimation of tropospheric aerosol extinction, surface area and volume: Maritime and desert-dust cases, J. Geophys. Res., 106, 3005-3018, (correction in Barnaba, F. and Gobbi, G. P., JGR, 107, D13, 10.1029/2002JD002340, 2002) 2001.

Barnaba, F. and Gobbi, G. P.: Modeling the aerosol extinction versus backscatter relationship in a mixed maritime-continental atmosphere: Lidar application and validation, J. Atmos. Ocean. Technol., accepted, 2003.

D’Almeida, G. A., Koepke, P., and Shettle, E. P., Atmospheric Aerosols, A. Deepack Publishing Co., Hampton, VA, 1991.

Dubovik, O., Holben, B., Eck, T. F., Smirnov, A., Kaufman, Y. J., King, M. D., Tanré, D., and Slutsker, I.: Variability of absorption and optical properties of key aerosol types observed in worldwide locations, J. Atmos. Sci., 59, 590-608, 2002.

Facchini, M. C., Mircea, M., Fuzzi, S., and Charlson, R. J.: Cloud albedo enhancement by surface-active organic solutes in growing droplets, Nature, 401, 257-259, 1999.

Franke, K., Ansmann, A., Muller, D., Althausen, D., Wagner, F., and Scheele, R.: One-year observations of particle lidar ratio over the tropical Indian Ocean with Raman lidar, Geophys. Res. Lett., 28, 24, 4559-4562, 2001.

Gasso, S., Hegg, D. A., Covert, D. S., Collins, D., Noone, K. J., Ostrom, E., Schmid, B., Russell, P. B., Livingston, J. M., Durkee, P. A., and Jonsson, H.: Influence of humidity on the aerosol scattering coefficient and its effect on the upwelling radiance during ACE 2, Tellus, 52B, 546-567, 2000.

Gobbi, G. P.: Polarization lidar returns from aerosols and thin clouds: a framework for the analysis. Appl. Opt., 37, 5505-5508, 1998.

Gobbi, G. P., Barnaba, F., Giorgi, R., and Santacasa, A.: Altituderesolved properties of a Saharan dust event over the Mediterranean, Atmos. Environ., 34, 5119-5127, 2000.

Gobbi, G. P., Barnaba, F., Blumthaler, M., Labow, G., and Herman, J. R.: Observed effects of particle non-sphericity on the retrieval of marine and desert dust aerosol optical depth by lidar, Atmos. Res., 61, 1-14, 2002.

Jacob, D. J.: Heterogeneous chemistry and tropospheric ozone, Atmos. Env., 34, 2131-2159, 2000.

Karyampudi, V. M., Palm, S. P., Reagen, J. A., Fang, H., Grant, W. B., Hoff, R. M., Moulin, C., Pierce, H. F., Torres, O., Browell, E. V., and Melfi, S. H.: Validation of the Saharan dust plume conceptual model using lidar, Meteosat and ECMWF data, Bull. Am. Met. Soc., 80, 1045-1075, 1999.

Kaufman, Y. J., Tanré D., and Boucher, O.: A satellite view of aerosols in the climate system, Nature, 419, 215-223, 2002.
Klett, J. D.: Lidar inversion with variable backscatter/extinction ratios, Appl. Opt., 24, 1638-1643, 1985.

Measures, R. M.: Laser Remote Sensing, J. Wiley, New York, 1984.

Mishchenko, M. I., Travis, L. D., Kahn, R. A., and West, R. A.: Modeling phase functions for dustlike tropospheric aerosols using a shape mixture of randomly oriented polydisperse spheroids, J. Geophys. Res., 102, 16 831-16847, 1997.

Mueller, D., Wandinger, U., and Ansmann, A.: Microphysical particle parameters from extinction and backscatter lidar data by inversion with regularization: Theory, Appl. Opt., 38, 2346-2357, 1999.

Penner, J. E., Andreae, M., Annegarn, H., Barrie, L., Feichter, J., Hegg, D., Jayaraman, A., Leaitch, R., Murphy, D., Nganga, J., and Pitari, G.: Aerosols, their Direct and Indirect Effects, in Climate Change 2001: The Scientific Basis, Cambridge University Press, Cambridge, 2001.

Putaud, J. P., Van Dingenen, R., Mangoni, M., Virkkula, A., Raes, F., Maring, H., Prospero, J. M., Swietlicki, E., Berg, O. J., Hillamo, R., and Makela, T.: Chemical mass closure and assessment of origin of the submicron aerosol in the marine boundary layer and the free troposphere at Tenerife during ACE 2, Tellus, 52B, 141-168, 2000.

Putaud, J. P., Van Dingenen, R., Dell'Acqua, A., Matta, E., Decesari, S., Facchini, M. C., and Fuzzi, S.: Size-segregated aerosol mass closure and chemical composition in Monte Cimone (I) during Minatroc, Atmos. Chem. Phys. Discuss., 3, 4097-4127, 2003.

Qing, P., Nakane, H., Sasano, Y., and Kitamura, S.: Numerical simulation of the retrieval of aerosol size distribution from multiwavelength laser radar measurements, Appl. Opt., 28, 52595265, 1989.

Raes F., Van Dingenen, R., Vignati, E., Wilson, J., Putaud, J. P., Seinfeld, J. H., and Adams, P.: Formation and cycling of aerosol in the global troposphere, Atmos. Environ., 34, 4215-4240, 2000.

Ramanathan, V., Crutzen, P. J., Kiehl, J. T., and Rosenfeld, D.: Aerosols, climate and the hydrological cycle, Science, 294, 2119-2124, 2001.

Rosenfeld, D.: TRMM observed first direct evidence of smoke from forest fires inhibiting rainfall, Geophys. Res. Lett., 26, 31053108, 1999.

Russell, P. B., Swissler, T. J., and McCormick, M. P.: Methodology for error analysis and simulation of lidar aerosol measurements, Appl. Opt., 18, 3783-3797, 1979.

Stohl, A. and Wotawa, G.: A method for computing single trajectories representing boundary layer transport, Atmos. Environ., 29, 3235-3239, 1995.

Sassen, K.: Indirect climate forcing over the western US from Asian dust storms, Geophys. Res. Lett., 29, 10, 10.1029/2001GL014051, 2002.

Veselovskii, I, Kolgotin, A., Griaznov, V., Mueller, D., Wandinger, U., and Whiteman, D. N.: Inversion with regularization for the retrieval of tropospheric aerosol parameters from multiwavelength lidar sounding, Appl. Opt., 41, 3685-3699, 2002. 